\title{
Analisis Metode Profile Matching dalam Merekomendasikan Tujuan Wisata Pendakian
}

\author{
Ratika Rizka Lubis', Handrizal ${ }^{2}$, Iin Parlina ${ }^{3}$, Irfan Sudahri Damanik ${ }^{4}$ \\ 1234Program Studi Sistem Informasi STIKOM Tunas Bangsa Pematang Siantar \\ Jln. Sudirman No 1,2,3 Blok A Pematang Siantar \\ Ratikarizka23@gmail.com
}

\begin{abstract}
Climbing is one of the extreme sports that is currently in great demand by many. Not just being a sport, climbing has also become a new hobby that is being loved today, especially for nature lovers organizations. Before climbing it is very necessary information that aims to determine which climbing tour to go. With the existence of suveral mountains in North Sumatra Province, many climbers have difficulty in determining which montain to choose, especially for lay climbers. Based on these problems, researchers raised the title of a climbing tour recommendation by using the profile matching method. The results of this study, namely the recommendation of climbing tourism destinations in Karo Regency is Gunung Deleng Kutu, with a score of 5. And occupies the highest value of the five climbing tours in Karo Regency.
\end{abstract}

\section{Keywords: Decission Suppord System, Climbing, Profile Matching}

Abstrak - Pendakian adalah salah satu olahraga ekstrim yang saat ini banyak diminati oleh banyak kalangan. Bukan hanya sekedar menjadi olahraga saja, mendaki juga sudah menjadi sebuah hobi baru yang sedang digandrungi saat ini, terkhusus organisasiorganisasi pecinta alam. Sebelum melakukan pendakian sangat diperlukannya informasi yang bertujuan untuk menentukan wisata pendakian mana yang akan dituju. Dengan adanya beberapa gunung di Kabupaten Karo, banyak pendaki yang kesulitan dalam menentukan gunung mana yang dijadikan pilihan, terlebih bagi para pendaki awam. Berdasarkan permasalahan tersebut, peneliti mengangkat judul rekomendasi tujuan wisata pendakian dengan menggunakan metode profile matching. Adapun tujuan dari penelitian ini yaitu untuk merekomendasikan tujuan wisata pendakian yang sesuai dengan menggunakan metode profile matching. Hasil dari penelitian ini yaitu rekomendasi tujuan wisata pendakian di Kabupaten Karo adalah gunung deleng kutu, dengan nilai 5. Dan menempati nilai tertinggi dari kelima wisata pendakian yang ada di Kabupaten Karo.

Kata kunci: Sistem Pendukung Keputusan, Pendakian, Profile Matching

\section{PENDAHULUAN}

Pendakian adalah perjalanan yang mempunyai tujuan untuk sampai ke puncak gunung, pendakian juga masuk dalam kategori olahraga ekstrim dan kegiatan rekreasi yang banyak diminati. Mendaki juga menjadi salah satu hobi baru yang sedang digandrungi akhir-akhir ini, biasanya dilakukan oleh orang yang mencintai petualangan dan para organisasi alam. Seorang pendaki biasanya memiliki alasan mengapa ingin terlibat dalam kegiatan ini. Misalnya adalah olahraga ini mempunyai tantangan tersendiri yang membuatnya merasakan kepuasan tersendiri karena bisa menaklukkan gunung, dan juga dapat menyatu dengan alam [1]. Sistem pendukung keputusan mampu menghasilkan informasi yang akurat bertujuan untuk memecahkan masalah-masalah tertentu [2]-[12]. 
Atau suatu sistem informasi dengan berbasis komputer yang memberikan hasil dari alternatif keputusan dalam membantu menangani permasalahan terstruktur menggunakan data dan model-model [13]. Profile matching adalah proses yang membandingkan GAP antara nilai alternatif dan juga kriteria. Gap yang bernilai 0 adalah nilai tertinggi, berarti nilai alternatif sama dengan kriteri. Ada dua kriteria dalam sub kriteria, yaitu core factor dan secondary faktor [14].

Kabupaten karo memiliki beberapa gunung yang sering dijadikan pilihan untuk wisata pendakian. Setiap gunungnya memiliki panorama yang berbeda dan memiliki ke khasannya masing-masing. Dengan adanya beberapa gunung yang dapat didaki membuat para pendaki terlebih pendaki pemula kesulitan dalam memilih gunung mana yang dijadikan tujuan pendakian. Beberapa teknik telah dikembangkan untuk mengambil keputusan tentang permasalahan-permasalahan yang dihadapi, salah satunya menggunakan sistem pendukung keputusan. Terdapat penelitian terdahulu yang dilakukan oleh [1] dengan judul penelitian "Sistem Pendukung keputusan menentukan tujuan wisata pendakian menggunakan metode technique for order preference by similarity to ideal solution “. Penelitian tersebut menggunakan 3 kriteria, dimana kesimpulan dari penulis adalah penelitian ini menghasilkan sebuah sistem yang dapat merekomendasikan tujuan wisata pendakian berdasarkan 3 kriteria. Perbedaan dengan penelitian yang penulis lakukan saat ini, terdapat di metode dan kriteria. Penulis menggunakan metode Profile Matching, dengan membuat sistem pendukung keputusan yang dapat merekomendasi para pendaki untuk memilih wisata pendakian sesuai dengan kriterianya dan kriteria yang digunakan penulis adalah ketinggian, lokasi, biaya, jalur/medan, suhu, dan kebersihan. Jurnal lain yang menjadi acuan dalam menyelesaian metode Profile Matching yaitu penelitian yang dilakukan oleh [14] yang membahas tentang rekomendasi cat dinding rumah berdasarkan konsumen dengan kriteria yang digunakan adalah kemasan, warna, kualitas, daya tutup, perlindungan. Kesimpulan dari penelitian ini bahwa metode Profile Matching dapat digunakan sebagai salah satu alat bantu yang dibutuhkan pengambil keputusan memilih cat dinding rumah yang dapat direkomendasikan kepada pihak konsumen. Pada penelitian ini, penulis akan mengangkat judul Analisis Metode Profile Matching Dalam Merekomendasikan Tujuan Wisata Pendakian. Diharapkan penulis dapat memberikan hasil yang terbaik dalam menentukan tujuan wisata pendakian. Pengumpulan data dilakukan dengan cara memberikan kuesioner/angket kepada 3 kelompok organisasi pecinta alam yang ada di Pematangsiantar, masing-masing organisasi diberikan 10 angket.

\section{METODOLOGI PENELITIAN}

\subsection{Analisa Data}

Pada penelitian ini menggunakan analisis kuantitatif. Teknik analisis data yang digunakan menggunakan jenis statistik inferensial. Statistik inferensial adalah statistik yang berkaitan dengan analisis data (sampel), kemudian diambil kesimpulan yang digeneralisasikan kepada seluruh populasi dan digunakan untuk menarik inferensi dari sampel ke populasi [15]. Kuesioner yang diberikan menggunakan linker 4 yang terdiri dari SS (Sangat Setuju), S (Setuju), R (Ragu), TS (Tidak Setuju). Penelitian ini dilakukan di Pematangsiantar. Data penelitian 
diperoleh dengan cara memberikan kuesioner/angket kepada 3 kelompok organisasi pecinta alam yang ada di Pematangsiantar masing-masing organisasi diberikan 10 angket. Berikut adalah data penelitian yang digunakan, dapat dilihat pada tabel 1.

Tabel 1. Data Penelitian

\begin{tabular}{|c|c|c|c|c|c|c|c|}
\hline No & Alternatif & Ketinggian & Lokasi & Biaya & Jalur & Suhu & Kebersihan \\
\hline 1 & Gunung Sibayak & Setuju & Setuju & Setuju & Ragu & Ragu & Ragu \\
\hline 2 & Gunung Sibuatan & Sangat Setuju & Setuju & Setuju & Setuju & Setuju & Ragu \\
\hline 3 & Gunung Sipiso-piso & Setuju & Ragu & Setuju & Ragu & Ragu & Ragu \\
\hline 4 & Gunung Deleng Kutu & Setuju & Ragu & Setuju & Setuju & Ragu & Setuju \\
\hline 5 & Gunung Barus & Ragu & Ragu & Setuju & Ragu & Setuju & Setuju \\
\hline
\end{tabular}

Tabel 2. Data Kriteria

\begin{tabular}{|c|c|c|c|c|}
\hline \multirow[t]{2}{*}{ No } & \multirow[t]{2}{*}{ Nama Kriteria } & \multirow[t]{2}{*}{ Profil Kriteria } & Nilai Bobot & Nilai Bobot \\
\hline & & & Sub Kriteria & (kriteria) \\
\hline \multirow[t]{4}{*}{1} & Kriteria 1 (C1) & \multirow[t]{4}{*}{5} & & \multirow[t]{4}{*}{$20 \%$} \\
\hline & Sub C1.1 & & $50 \%$ & \\
\hline & Sub C1.2 & & $30 \%$ & \\
\hline & Sub C1.3 & & $20 \%$ & \\
\hline \multirow[t]{4}{*}{2} & Kriteria 2 (C2) & \multirow[t]{4}{*}{3} & & \multirow[t]{4}{*}{$15 \%$} \\
\hline & Sub C2.1 & & $50 \%$ & \\
\hline & Sub C2.2 & & $40 \%$ & \\
\hline & Sub C2.3 & & $10 \%$ & \\
\hline \multirow[t]{4}{*}{3} & Kriteria 3(C3) & \multirow[t]{4}{*}{2} & & \multirow[t]{4}{*}{$10 \%$} \\
\hline & Sub C3.1 & & $40 \%$ & \\
\hline & Sub C3.2 & & $30 \%$ & \\
\hline & Sub C3.3 & & $30 \%$ & \\
\hline \multirow[t]{4}{*}{4} & Kriteria 4(C4) & \multirow[t]{4}{*}{4} & & \multirow[t]{4}{*}{$20 \%$} \\
\hline & Sub C4.1 & & $50 \%$ & \\
\hline & Sub C4.2 & & $30 \%$ & \\
\hline & Sub C4.3 & & $20 \%$ & \\
\hline \multirow[t]{4}{*}{5} & Kriteria 5(C5) & \multirow[t]{4}{*}{1} & & \multirow[t]{4}{*}{$5 \%$} \\
\hline & Sub C5.1 & & $40 \%$ & \\
\hline & Sub C5.2 & & $30 \%$ & \\
\hline & Sub C5.3 & & $30 \%$ & \\
\hline \multirow[t]{4}{*}{6} & Kriteria 6(C6) & \multirow[t]{4}{*}{6} & & \multirow[t]{4}{*}{$30 \%$} \\
\hline & Sub C6.1 & & $50 \%$ & \\
\hline & Sub C6.2 & & $40 \%$ & \\
\hline & Sub C6.3 & & $10 \%$ & \\
\hline
\end{tabular}

Dengan nilai asumsi bobot sebgai berikut :

Tabel 3. Nilai Asumsi bobot

\begin{tabular}{|c|l|c|}
\hline No & Keterangan Bobot & Nilai Bobot \\
\hline 1 & Sangat Setuju & 5 \\
\hline 2 & Setuju & 4 \\
\hline 3 & RaguRagu & 3 \\
\hline 4 & Tidak setuju & 2 \\
\hline
\end{tabular}

Sedangkan data yang digunakan sebagai alternatif dapat dilihat pada tabel 4. berikut. 
Tabel 4. Data Alternatif

\begin{tabular}{|c|c|l|}
\hline No & Alternatif & \multicolumn{1}{|c|}{ Nama Alternatif } \\
\hline 1 & A1 & Gunung Sibayak \\
\hline 2 & A2 & Gunung Sibuatan \\
\hline 3 & A3 & Gunung Sipiso-piso \\
\hline 4 & A4 & Gunung Deleng Kutu \\
\hline 5 & A5 & Gunung Barus \\
\hline
\end{tabular}

\subsection{Pendakian}

Pendakian merupakan suatu kegiatan fisik atau olahraga yang dilakukan di alam bebas. Hal ini biasanya dilakukan oleh orang-orang yang menyukai petualangan. Tidak hanya cukup untuk berolahraga saja, mendaki juga menjadi sebuah rekreasi yang menikmati dan melihat keindahan alam dari atas puncak gunung dan menawarkan keindahan alam yang begitu sempurna. Sebuah tantangan yang dijalani saat proses pendakian akan memberikan rasa antusias dan pemenuhan rasa penaklukan dunia pada saat tiba dipuncaknya. Menyaksikan keindahan dari atas puncak adalah hasil dari semuanya.

\subsection{Algoritma Profile Matching}

Metode profile matching dapat memberikan solusi untuk pengambilan keputusan yang objektif dan memiliki tujuan yang jelas [16] Profile matching adalah metode yang sering dipakai sebagai mekanisme dalam pengambilan keputusan dengan mengasumsikan bahwa terdapat tingkat variabel prediktor yang ideal yang harus dipenuhi oleh subyek yang diteliti, bukannya tingkat minimal yang harus dipenuhi atau dilewati. Metode profile matching akan menghasilkan rangking yang sesuai dan merekomendasikan [17].

Tahapan-tahapan pada metode profile matching [18] adalah sebagai berikut:

1. Pemetaan gap

Menghitung nilai gap untuk masing-masing kriteria. Proses penilaian nilai gap yaitu,

Gap $=$ PA - PK

Dimana:

PA : Profile Alternatif

PK: Profile kriteria

2. Pembobotan

Setelah didapatkan nilai gap maka setiap nialai gap diberi bobot nilai dengan patokan tabel bobot nilai gap.

Tabel 5. Bobot Nilai Gap

\begin{tabular}{|c|c|c|l|}
\hline No & Selisih Gap & Bobot Nilai & \multicolumn{1}{c|}{ Keterangan } \\
\hline 1. & 0 & 6 & Tidak ada gap ( kompetensi sesuai yang dibutuhkan) \\
\hline 2. & 1 & 5,5 & Kompetensi individu kelebihan 1 tingkat/level \\
\hline 3. & -1 & 5 & Kompetensi individu kurang 1 tingkat/level \\
\hline 4. & 2 & 4,5 & Kompetensi individu kelebihan 2 tingkat/level \\
\hline 5. & -2 & 4 & Kompetensi individu kurang 2 tingkat/level \\
\hline 6. & 3 & 3,5 & Kompetensi individu kelebihan 3 tingkat/level \\
\hline 7. & -3 & 3 & Kompetensi individu kurang 3 tingkat/level \\
\hline
\end{tabular}




\begin{tabular}{|c|c|c|l|}
\hline No & Selisih Gap & Bobot Nilai & \multicolumn{1}{c|}{ Keterangan } \\
\hline & & & \\
\hline 8. & 4 & 2,5 & Kompetensi individu kelebihan 4 tingkat/level \\
\hline 9. & -4 & 2 & Kompetensi individu kurang 4 tingkat/level \\
\hline 10. & 5 & 1,5 & Kompetensi individu kurang 5 tingkat/level \\
\hline 11. & -5 & 1 & Kompetensi individu kurang 5 tingkat/level \\
\hline
\end{tabular}

3. Menghitung Core Factor dan Secondary Factor

Langkah ketiga adalah perhitungan nilai core factor (faktor utama) dan nilai secondary factor (faktor pendukung). Adapun rumus perhitungannya sebagai berikut :

core factor : $\mathrm{NCF}=\frac{\sum N C}{\sum I C}$

secondary factor $: \mathrm{NSF}=\frac{\sum N S}{\sum I S}$

Keterangan:

NCF : Nilai rata-rata core factor

NSF : Nilai rata-rata secondary factor

NC : Jumlah total nilai core factor

IC : Jumlah total nilai item core factor

NS: Jumlah total nilai secondary factor

IS : Jumlah total nilai item secondary factor

4. Perhitungan Nilai Total

Rumus untuk perhitungan nilai total ini adalah:

$(\mathrm{X}) \% \cdot \mathrm{NCF}+(\mathrm{X}) \% \cdot \mathrm{NSF}=\mathrm{N}$

Keterangan :

NCF : Nilai rata-rata core factor

NSF : Nilai rata-rata secondary factor

$\mathrm{N}$ : Nilai total dari aspek

(X)\% : Nilai persen yang diinputkan

\section{HASIL DAN PEMBAHASAN}

\subsection{Analisa Algoritma Profile Matching}

Langkah - langkah dalam menyelesaikan perhitungan manual metode profile matching:

1. Menormalisasi data berdasarkan nilai bobot profile matching yaitu sebagai berikut:

Tabel 6. Nilai Normalisasi Bobot

\begin{tabular}{|c|l|c|c|c|c|c|c|}
\hline No & \multicolumn{1}{|c|}{ Alternatif } & Ketinggian & Lokasi & Biaya & Jalur & Suhu & Kebersihan \\
\hline 1 & Gunung Sibayak & 4 & 4 & 4 & 3 & 3 & 3 \\
\hline 2 & Gunung Sibuatan & 5 & 4 & 4 & 4 & 4 & 3 \\
\hline 3 & Gunung Sipiso-piso & 4 & 3 & 4 & 3 & 3 & 3 \\
\hline 4 & Gunung Deleng Kutu & 4 & 3 & 4 & 4 & 3 & 4 \\
\hline 5 & Gunung Barus & 3 & 3 & 4 & 3 & 4 & 4 \\
\hline
\end{tabular}


2. Menghitung nilai Gap dan Mapping Gap dari masing-masing kriteria

Tabel 7. Nilai Gap

\begin{tabular}{|c|l|c|c|c|c|c|c|}
\hline No. & \multicolumn{1}{|c|}{ Alternatif } & Ketinggian & Lokasi & Biaya & Jalur & Suhu & Kebersihan \\
\hline 1. & Gunung Sibayak & -1 & 1 & 2 & -1 & 2 & -3 \\
\hline 2. & Gunung Sibuatan & 0 & 1 & 2 & 0 & 3 & -3 \\
\hline 3. & Gunung Sipiso-piso & -1 & 0 & 2 & -1 & 2 & -3 \\
\hline 4. & Gunung Deleng Kutu & -1 & 0 & 2 & 0 & 2 & -2 \\
\hline 5. & Gunung Barus & -2 & 0 & 2 & -1 & 3 & -2 \\
\hline
\end{tabular}

3. Menghitung nilai Mapping Gap yang bersumber dari analisis Gap

Tabel 8. Mapping Gap

\begin{tabular}{|c|l|c|c|c|c|c|c|}
\hline No & \multicolumn{1}{|c|}{ Alternatif } & Ketinggian & Lokasi & Biaya & Jalur & Suhu & Kebersihan \\
\hline 1. & Gunung Sibayak & 5,0 & 5,5 & 4,5 & 5,0 & 4,5 & 3,0 \\
\hline 2. & Gunung Sibuatan & 6,0 & 5,5 & 4,5 & 6,0 & 3,5 & 3,0 \\
\hline 3. & Gunung Sipiso-piso & 5,0 & 6,0 & 4,5 & 5,0 & 4,5 & 3,0 \\
\hline 4. & Gunung Deleng Kutu & 5,0 & 6,0 & 4,5 & 6,0 & 4,5 & 4,0 \\
\hline 5. & Gunung Barus & 4,0 & 6,0 & 4,5 & 5,0 & 3,5 & 4,0 \\
\hline
\end{tabular}

4. Perhitungan Core Factor dan Secondary Factor

Tabel 5. Nilai Core Factor dan Secondary Factor

\begin{tabular}{|l|c|c|c|}
\hline \multirow{4}{*}{ Core Factor (70\%) } & C1 & C4 & C6 \\
\cline { 2 - 4 } & 5 & 5 & 3 \\
\cline { 2 - 4 } & 6 & 6 & 3 \\
\cline { 2 - 4 } & 5 & 5 & 3 \\
\cline { 2 - 4 } & 5 & 6 & 4 \\
\cline { 2 - 4 } & 4 & 5 & 4 \\
\hline \multirow{5}{*}{ Secondary Factor (30 \%) } & $\mathbf{C 2}$ & $\mathbf{C 3}$ & $\mathbf{C 5}$ \\
\cline { 2 - 4 } & 5,5 & 4,5 & 4,5 \\
\cline { 2 - 4 } & 5,5 & 4,5 & 3,5 \\
\cline { 2 - 4 } & 6 & 4,5 & 4,5 \\
\cline { 2 - 4 } & 6 & 4,5 & 4,5 \\
\cline { 2 - 4 } & 6 & 4,5 & 3,5 \\
\hline
\end{tabular}

Perhitungan Core Factor :

$$
\begin{aligned}
& \mathrm{NCF}=\frac{5+5+3}{3}=4,33 \\
& \mathrm{NCF}=\frac{6+6+3}{3}=5 \\
& \mathrm{NCF}=\frac{5+5+3}{3}=4,33 \\
& \mathrm{NCF}=\frac{5+6+4}{3}=5 \\
& \mathrm{NCF}=\frac{4+5+4}{3}=4,33
\end{aligned}
$$

Perhitungan Secondary Factor :

$$
\begin{aligned}
& \mathrm{NSF}=\frac{5,5+4,5+4,5}{3}=4,83 \\
& \mathrm{NSF}=\frac{5,5+4,5+3,5}{3}=4,5
\end{aligned}
$$




$$
\begin{aligned}
& \mathrm{NSF}=\frac{6+4,5+4,5}{3}=5 \\
& \mathrm{NSF}=\frac{6+4,5+4,5}{3}=5 \\
& \mathrm{NSF}=\frac{6+4,5+3,5}{3}=4,66
\end{aligned}
$$

5. Perhitungan hasil akhir dan perangkingan

A1. $(0,7 \times 4,33)+(0,3 \times 4,83)=4,48$

A2. $(0,7 \times 5)+(0,3 \times 4,5)=4,85$

A3. $(0,7 \times 4,33)+(0,3 \times 5)=4,53$

A4. $(0,7 \times 5)+(0,3 \times 5)=5$

A5. $(0,7 \times 4,33)+(0,3 \times 4,66)=4,43$

\subsection{Hasil}

Untuk mendapatkan hasil berupa rekomendasi wisata pendakian maka pada tahap selanjutnya dapat dilakukan dengan cara pengujian menggunakan aplikasi vb.net . Tampilan aplikasi rekomendasi tujuan wisata pendakian, seperti gambar 1 .

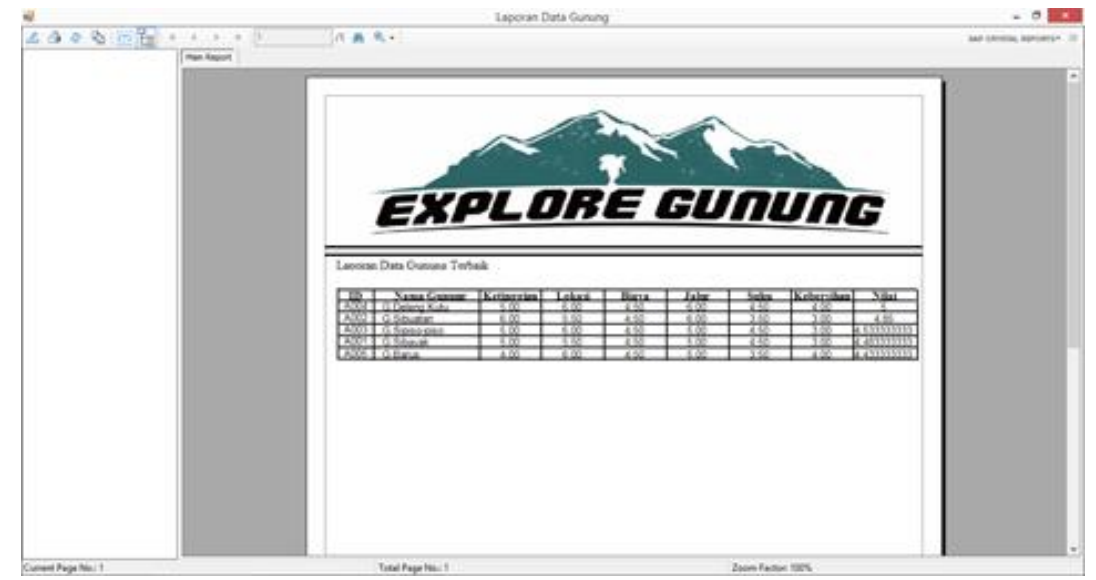

Gambar 1. Form Hasil Profile Matching

\subsection{Pembahasan}

Setelah rancangan program selesai, dilakukan uji sistem sebelum dilaksankannya implementasi sistem untuk melihat apakah hasil program telah selesai atau tidak dengan yang diharapkan. Program yang telah dirancang dilakukan uji sistem dengan teknik statis, dimana telah dilakukan uji coba sistem untuk perangkat keras dan perangkat lunak yang dibutuhkan untuk menjalankan program, desaindetail sistem, aturan-aturan format sistem, beserta test running program.

\section{KESIMPULAN}

Setelah analisis data perancangan dan perhitungan komputerisasi yang telah dilakukan, maka diperoleh kesimpulan dalam menentukan wisata pendakian sebagai berikut: 
a. Aplikasi yang dibuat hanya sebagai alat bantu yang memberikan informasi kepada user atau pihak yang membutuhkan dalam menentukan wisata pendakian.

b. Permasalahan dalam menentukan rekomendasi wisata pendakian dapat diselesaikan dengan menggunakan metode Profile Matching.

c. Sistem memberikan solusi rekomendasi kepada pengguna ( user ) sesuai dengan kriteria dan bobot yang ditentukan diawal sebelum perhitungan.

d. Sistem yang dibangun hanya sebgai alat bantu untuk memberikan informasi kepada para pendaki sebagai bahan pertimbangan dalam mengambil keputusan.

\section{DAFTAR PUSTAKA}

[1] Y. Giryanto, G. Abdillah, and D. Nursantika, "SISTEM PENDUKUNG KEPUTUSAN MENENTUKAN TUJUAN WISATA PENDAKIAN MENGGUNAKAN METODE TECHNIQUE FOR ORDER," pp. 1-6, 2017.

[2] T. Imandasari, A. Wanto, and A. P. Windarto, "Analisis Pengambilan Keputusan Dalam Menentukan Mahasiswa PKL Menggunakan Metode PROMETHEE," Jurnal Riset Komputer (JURIKOM), vol. 5, no. 3, pp. 234-239, 2018.

[3] A. Wanto and E. Kurniawan, "Seleksi Penerimaan Asisten Laboratorium Menggunakan Algoritma AHP Pada AMIK-STIKOM Tunas Bangsa Pematangsiantar," Jurnal Informatika dan Komputer (JIKO), vol. 3, no. 1, pp. 11-18, 2018.

[4] A. Wanto and H. Damanik, "Analisis Penerapan Sistem Pendukung Keputusan Terhadap Seleksi Penerima Beasiswa BBM (Bantuan Belajar Mahasiswa) Pada Perguruan Tinggi Menggunakan Metode Simple Additive Weighting (SAW) (Studi Kasus : AMIK Tunas Bangsa Pematangsiantar)," in Seminar Nasional Rekayasa (SNTR) II, 2015, no. 2, pp. 323-333.

[5] M. Widyasuti, A. Wanto, D. Hartama, and E. Purwanto, "Rekomendasi Penjualan Aksesoris Handphone Menggunakan Metode Analitycal Hierarchy Process (AHP)," Konferensi Nasional Teknologi Informasi dan Komputer (KOMIK), vol. I, no. 1, pp. 27-32, 2017.

[6] S. Sundari, A. Wanto, Saifullah, and I. Gunawan, "Sistem Pendukung Keputusan Dengan Menggunakan Metode Electre Dalam Merekomendasikan Dosen Berprestasi Bidang Ilmu Komputer (Study Kasus di AMIK \& STIKOM Tunas Bangsa)," in Seminar Nasional Multi Disiplin Ilmu, 2017, pp. 1-6.

[7] R. A. Hutasoit, S. Solikhun, and A. Wanto, "Analisa Pemilihan Barista dengan Menggunakan Metode TOPSIS (Studi Kasus: Mo Coffee)," KOMIK (Konferensi Nasional Teknologi Informasi dan Komputer), vol. 2, no. 1, pp. 256-262, 2018.

[8] N. Rofiqo, A. P. Windarto, and A. Wanto, "Penerapan Metode VIKOR Pada Faktor Penyebab Rendahnya Minat Mahasiswa Dalam Menulis Artikel Ilmiah," Seminar Nasional Sains \& Teknologi Informasi (SENSASI), vol. 1, no. 1, pp. 228-237, 2018.

[9] L. P. Purba, A. P. Windarto, and A. Wanto, "Faktor Terbesar Rendahnya Minat Ber-KB (Keluarga Berencana) dengan Metode ELECTRE II," Seminar Nasional Sains \& Teknologi Informasi (SENSASI), vol. 1, no. 1, pp. 369-374, 2018.

[10] M. Masitha, D. Hartama, and A. Wanto, "Analisa Metode (AHP) pada Pembelian Sepatu Sekolah Berdasarkan Konsumen," Seminar Nasional Sains \& Teknologi Informasi (SENSASI), vol. 1, no. 1, pp. 338-342, 2018.

[11] S. R. Ningsih, D. Hartama, A. Wanto, I. Parlina, and Solikhun, "Penerapan Sistem Pendukung Keputusan Pada Pemilihan Objek Wisata di Simalungun," in Seminar Nasional Teknologi Komputer \& Sains (SAINTEKS), 2019, pp. 731-735.

[12] S. Sundari, S. M. Sinaga, I. S. Damanik, and A. Wanto, "Sistem Pendukung Keputusan Pemilihan Peserta Olimpiade Matematika SMA Swasta Teladan Pematangsiantar Dengan Metode Electre," in Seminar Nasional Teknologi Komputer \& Sains (SAINTEKS), 2019, pp. 793-799.

[13] A. P. Windarto, "Implementasi metode topsis dan saw dalam memberikan reward 
pelanggan," no. April, 2017.

[14] S. R. Rani, R. Rizka, and A. Perdana, "Analisis Metode Profile Matching Pada Rekomendasi Cat Dinding Rumah Berdasarkan Konsumen," vol. 17, 2018.

[15] M. R. Munandar, E. S. Astuti, and M. S. Hakam, "( Studi Pada Pekerja bagian Produksi PT . SEKAWAN KARYATAMA MANDIRI Sidoarjo )," vol. 9, no. 1, pp. 1-9, 2014.

[16] A. Sudarmadi and E. Santoso, "Sistem Pendukung Keputusan Pemilihan Personel Homeband Universitas Brawijaya Menggunakan Metode Profile Matching," vol. 1, no. 12, pp. 1788-1796, 2017.

[17] J. Fitriana and E. F. Ripanti, "Sistem Pendukung Keputusan Pemilihan Mahasiswa Berprestasi dengan Metode Profile Matching ( Studi Kasus : Fakultas Teknik UNTAN ),” vol. 6, no. 4, pp. 153-160, 2018.

[18] M. Raihan and S. Abidah, "Penerapan Metode Profile Matching Pada Proses Pemilihan Lokasi Perumahan," pp. 827-836. 